\title{
Assessment for Intimate Partner Violence: Where Do We Stand?
}

Patricia Janssen, PhD, Hagit Dascal-Weichbendler, MD, and Margaret McGregor, MD

In recognition of a growing body of literature linking violence to health outcomes, recent systematic reviews in North America have examined the utility of screening. The US Preventive Services Task Force concluded in 2004 that there is insufficient evidence for or against routine universal screening for intimate partner violence. ${ }^{1}$ The Canadian Task Force on Preventive Health Care had come to a similar conclusion in 2003. ${ }^{2}$ These findings have been widely interpreted by the primary health care community as providing sufficient reason to avoid routine or periodic inquiry about intimate partner violence. ${ }^{3}$ On the other hand, professional practice organizations, including the American Medical Association, ${ }^{4}$ American Academy of Family Physicians, ${ }^{5}$ and the American College of Obstetricians and Gynecologists, ${ }^{6}$ have published guidelines promoting screening. These bulletins vary in their content and degree of prescriptiveness in relation to screening. It is hardly surprising therefore, that family medicine physicians remain uncertain about their role with respect to assessment for intimate partner violence.

Providers should be cautioned about interpreting "insufficient evidence for screening" to mean that inquiry about intimate partner violence has no place in a routine health assessment. Although secondary prevention, by definition, is justified only when there is an available intervention that is known to improve prognosis, ${ }^{7}$ another equally justifiable purpose for asking about intimate partner

Submitted 29 July 2005; revised 19 December 2005; accepted 23 December 2005.

From the Departments of Family Practice (PJ, MM), and Health Care and Epidemiology, University of British Columbia, Vancouver, BC, Canada; and Department of Family Medicine (HD-W), Technion-Israel Institute of Technology, Haifa, Israel.

Conflict of interest: none declared.

Corresponding author: Patricia Janssen, PhD, Department of Health Care and Epidemiology, University of British Columbia, 5804 Fairview Avenue, Vancouver, BC Canada V6T 1 Z3 (E-mail: pjanssen@interchange.ubc.ca). violence is to identify potential health hazards. Intimate partner violence is reported to be associated with a plethora of physical ${ }^{8}$ and mental health concerns, ${ }^{9,10}$ including arthritis, migraine, stomach ulcers, spastic colon, chronic pain, and depression. North American population-based studies have reported an 8-fold increase in perinatal death associated with exposure to intimate partner violence during pregnancy. ${ }^{11,12}$ When primary care physicians routinely ask about smoking as part of patient history taking, they do not do so in the belief that asking the question will stop their patients from smoking. Instead, knowledge of smoking status may guide the physician to undertake more frequent monitoring of cardiovascular and pulmonary health status, including measurement of blood pressure, evaluation of exercise tolerance, etc. Similarly, asking about intimate partner violence and obtaining a positive response identifies an opportunity for prevention of health-related sequelae.

In addition, screening allows the physician to become acquainted with new contexts of a patient's life. Asking about violence exposure may give the physician insight into the etiology of health problems, permitting definitive treatment rather than simply palliating their symptoms. For example, treatment of depression with antidepressants is not likely to be successful without addressing the battering that has given rise to the depression.

Furthermore, "insufficient evidence" is not the same as "evidence supporting lack of efficacy." Two randomized intervention trials for abused women in pregnancy, both cited by the US Preventive Services Task Force, reported reductions in violence risk scores up to 18 months postintervention, which consisted of counseling women on measures they could undertake to enhance their safety at home. ${ }^{13,14}$ An important component of safety counseling is to provide information about women's shelters. Both task forces cite a study by Sullivan that demonstrated a reduction of physical 
violence and improvement of quality of life for 2 years following a stay in a women's shelter accompanied by advocacy services. ${ }^{15}$ The US Preventive Services Task Force concluded that benefits of referral to a shelter outweigh harms and recommended that clinicians provide this service to eligible patients.

One state-wide survey of family physicians reported that fewer than $10 \%$ routinely screen for intimate partner violence. ${ }^{16}$ Barriers to screening expressed by physicians include inadequate training, time constraints, and lack of resources to address interpersonal violence. ${ }^{17}$ Physicians interviewed as part of a qualitative study attempting to explore these barriers did not believe that intimate partner violence was a medical issue or that finding solutions was within their scope of practice. ${ }^{18}$ They said "we are not looking for new problems to screen for." ${ }^{18}$ In this environment of reticence, medical students have been shown to have difficulty applying classroom-acquired knowledge of intimate partner violence in their clinical placements. ${ }^{19}$ In a recent informal survey of eighteen preceptors for second year medical students at the University of British Columbia by the first author, none of the family medicine preceptors was assessing for intimate partner violence among either symptomatic or asymptomatic patients. Medical students assigned to these preceptors indicated that they asked their patients about intimate partner violence only when their preceptors were out of the room. An Arizona survey of medical students' knowledge and attitude regarding screening for intimate partner violence indicated that no improvement in perceived ability to identify and deal with intimate partner violence had taken place during a 6 year period ending in 2001. The authors stressed the need to emphasize "hands-on" training and improve the competence and confidence of medical providers in clinical settings. ${ }^{20}$

Guidelines in general urge physicians and other health care providers to remain current in their knowledge of provider and patient barriers to identification, treatment, and prevention of intimate partner violence. ${ }^{4}$ At a minimum, physicians are advised to ask about the possibility of abuse in presentations with unexpected or unexplained stress, anxiety, depression, substance abuse, injuries, and chronic somatic symptoms. As part of routine inquiry about stress, family function (particularly during transitions such as pregnancy, sep- aration, and divorce), and alcohol and drug use during periodic checkups, the physician is cautioned to be alert to the possibility of spousal abuse. ${ }^{21}$ The Canadian Task Force on Preventive Health Care, although not advocating "screening," stresses the importance of asking about violence when clinically relevant. ${ }^{22}$ As our knowledge of the physical and mental health effects of intimate partner violence expands, asking about abuse becomes relevant in many clinical situations.

Where do we stand? Public health practice defines a series of steps to approaching emerging health or health-related problems. ${ }^{23}$ First the problem needs to be defined and measured. In the context of intimate partner violence, this requires that family medicine physicians create a climate that facilitates disclosure, discussion, and documentation. This involves interviewing the woman separately from partners and older children, normalizing the process by indicating that the questions are part of routine inquiry, and by gaining an appreciation of the vulnerability caused by the fear and shame many victims feel. Second, risk factors must be elucidated. This step calls for exploration and documentation of precipitating circumstances and characteristics of both the perpetrator and the victim. Third, searching for effective interventions necessitates the facilitation of studies in clinical and public health settings that seek to promote our understanding of prevention and management, both for the perpetrator and the victim.

Finally, we must implement effective strategies as they become available. Two concepts familiar to public health deserve mention here. ${ }^{24}$ Resiliency refers to the ability of women to overcome barriers to maintaining health. In the tension between waiting for definitive studies before attempting interventions, we must not ignore the ability of victims themselves to find solutions. Simple identification of the problem and a supportive relationship with a physician may give someone the added strength they need to leave a dangerous situation. When shelters may be in short supply, for example, women who feel empowered may seek haven with friends, neighbors, or family. The physician who has developed superlative skills in patient-centered interviewing will support this process. Another cornerstone of public health is harm reduction. Physicians' frustration with a woman's inability to leave an abusive situation ${ }^{18}$ may be tempered with a change in objective toward reduced violence expo- 
sure through extensive safety planning, as opposed to exiting the relationship.

In light of the current explosion of information about the association of intimate partner violence with health outcomes, family physicians have a responsibility to train physicians to assess for intimate violence as a means of monitoring health status. We must be prepared to implement preventive measures as effective techniques are identified. In the meantime we can support and empower women to generate individual strategies to reduce harm to themselves and their children.

\section{References}

1. Nelson H, Nygren P, McInerney Y, Klein J. Screening women and elderly adults for family and intimate partner violence: a review of the evidence for the U.S. Preventive Services Task Force. Ann Intern Med 2004;140:387-96.

2. Wathen C, MacMillan H. Interventions for violence against women: scientific review. JAMA 2003;289: 589-600.

3. Shaw D. Screening for domestic violence. J Obstet Gynaecol Can 2003;25:918-21.

4. American Medical Association. Diagnostic and treatment guidelines for domestic violence. Arch Fam Med. 1992;1:39-47.

5. American Academy of Family Physicians. Family and intimate partner violence and abuse. Available at: www.aafp.org/x16506.xml. Accessed Dec 9, 2005.

6. American College of Obstetrics and Gynecology. Domestic violence: educational bulletin number 257. Washington (DC); 1999.

7. Rothman K. Epidemiology: an introduction. Oxford: University Press; 2002.

8. Coker A, Smith P, Bethea L, King M, Keown R. Physical health consequences of physical and psychological intimate partner violence. Arch Fam Med 2003;9:451-7.

9. Nixon R, Resick P, Nishith P. An exploration of comorbid depression among female victims of intimate partner violence with posttraumatic stress disorder. J Affect Disord 2004;82:315-20.

10. Romito P, Turan J, De Marchi M. The impact of current and past interpersonal violence on women's mental health. Soc Sci Med 2005;60:1717-27.

11. Janssen P, Holt V, Sugg N, Emanuel I, Critchlow C,
Henderson A. Intimate partner violence and adverse pregnancy outcomes: a population-based study. Am J Obstet Gynecol 2003;188:1341-7.

12. Lipsky S, Holt V, Easterling T, Critchlow C. Impact of police-reported intimate partner violence during pregnancy on birth outcomes. Obstet Gynecol 2003; 102:557-64.

13. McFarlane J, Soeken K, Wiist W. An evaluation of interventions to decrease intimate partner violence to pregnant women. Public Health Nurs 2000;17: $443-51$.

14. Parker B, McFarlane J, Soeken K, Silva C, Reel S. Testing an intervention to prevent further abuse to pregnant women. Res Nurs Health 1999;22:59-66.

15. Sullivan C, Bybee D. Reducing violence using community-based advocacy for women with abusive partners. J Consult Clin Psychol 1999;67:43-53.

16. Lapidus G, Cooke M, Gelven E, Sherman K, Duncan M, Banco L. A statewide survey of domestic violence screening behaviours among pediatricians and family physicians. Arch Pediat Adolesc Med 2002;156:332-6.

17. Waalen J, Goodwin M, Spitz A, Petersen R, Saltzman L. Screening for intimate partner violence by health care providers. Am J Prev Med 2000;19:230-7.

18. Zink T, Regan S, Goldenbar L, Pabst S, Rinto B. Intimate partner violence: what are physicians' perceptions? J Am Board Fam Pract 2004;17:332-40.

19. Janssen P, Landolt M, Grunfeld A. Assessing for domestic violence exposure in primary care settings: the transition from classroom to clinical practice. J Interpers Viol 2003;18:623-33.

20. Miller A, Coonrod D, Brady M. Medical student training in domestic violence: a comparison of students entering residency training in 1995 and 2001. Teach Learn Med 2004;16:3-6.

21. Ferris L. Intimate partner violence. BMJ 2004;328: 595-6.

22. MacMillan HL, Wathen CN. Prevention and treatment of violence against women: systematic review and recommendations. London $(\mathrm{ON})$ : Canadian Task Force on Preventive Health Care (CTFPHC); 2001 Sep 62 p. Technical report no. 01-4.

23. Saltzman L, Green Y, Marks J, Thacker S. Violence against women as a public health issue. Am J Prev Med 2000;19:325-9.

24. Ontario Public Health Association. Public health and violence prevention-maintaining the momentum. A position paper. Toronto; 2003. 